\title{
Design of Integral Constant State Feedback Controller Using Ackermann's Function
}

\author{
${ }^{1}$ S.Janani \\ ${ }^{I}$ PG Scholar (M.E), Department of ECE, Sri Eshwar College of Engineering, Coimbatore, India
}

\begin{abstract}
This paper presents the design of State Feedback Controller to implement it at Coupled Two Tank Liquid Level System. The liquid level in the coupled tank is controlled by using feedback as required and also to understand the habit and effectiveness of Integral Control State Feedback Controller. The design was implemented using second order system in the coupled tank. The State Feedback Controller is designed using Ackermann's formula based on pole placement method. The Ackermann's method, besides being useful for single-input systems, may also find application to control a multi-input system through a single input. A state feedback control is linear combinations of state variables. State feedback focuses on time-domain features of the system responses. The necessary and sufficient condition to be satisfied by the system for arbitrary pole placement is the system be completely state controllable.
\end{abstract}

Keywords: Integral control State feedback controller, Ackermann's formula, Coupled two tank liquid level system, Pole Placement technique.

\section{Introduction}

Coupled tank liquid level system consists of double tank mounted on a reservoir for liquid storage. At the centre of the double tank, there placed a baffle to divide it into two different small tanks. At the base of each tank, there have a flow valve connected to reservoir. Each of the small tanks has water pump to pump water from reservoir. Capacitance sensor is used to detect the level of the water. To measure the liquid level a scale is placed in front of the tank. This equipment finds wide applications in the food processing and chemical industries.

The level of the liquid return to the reservoir is controlled using state feedback control system. State feedback will control the water pump so that liquid in tank 2 is maintained as required. The classical method is applicable to the linear time-invariant systems. It is generally restricted to single-input-single-output systems as this approach becomes highly cumbersome for use in multiple-input-multiple-output systems. Also the classical method reveals only the system output for a given input and provides no information regarding the internal states of the system. There may be situations, where the output of a system is stable and yet some of the system elements may have a tendency to exceed their specified rating. To overcome the above drawbacks a new approach called state variable approach is introduced which gives the information about the states of the system variables along with the output. MATLAB has been used as graphic user interface and as simulation respectively.

\section{Problem Statement}

Nowadays, the world economy is down and hence many of the countries are facing the same problem. So to overcome this problem, many factories must cut cost in term of workforce to maintain the same price or to reduce the price of their product. The thing that can overtake human responsibility is a computer. But the computer cannot work itself without human to set the suitable program for it, so the program that have been used here is the controller.

All equipment in this world need to be operated automatically without human attendant. To implement this, we must use a controller with a medium to control it so that the machine or equipment can run automatically. Normally PID and Fuzzy Logic controllers are widely used to control many of the instrument or machine, but in this project the controller that have been used is Integral Control State Feedback Controller.

In real time, the liquid level in tank 2 will be controlled by the Integral Control State Feedback Controller. This plant system is in second order system and the Integral Control State Feedback Controller will be derived directly from the plant using pole placement method. We cannot manipulate anything of the controller value by using pole placement method. 


\section{Coupled Two Tank Liquid System}

The control of liquid level in tanks and flow between tanks is a basic problem in the process industries. In vital industries like Petro-chemical, Paper making and Water treatment industries have the coupled tanks processes of chemical or mixing treatment in the tanks, the level of fluid in the tanks and interacting between tanks must be controlled. It is essential for control system engineers to understand how coupled tank control systems work and how the level control problem is solved. The problem of level control in coupled tank processes are interacting characteristic and system dynamics. The new variable is the flow rate $\mathrm{Q}_{\mathrm{c}}$ of fluid out of Tank 2 through valve C. Figure 1 shows the general block diagram of coupled two tank liquid system.

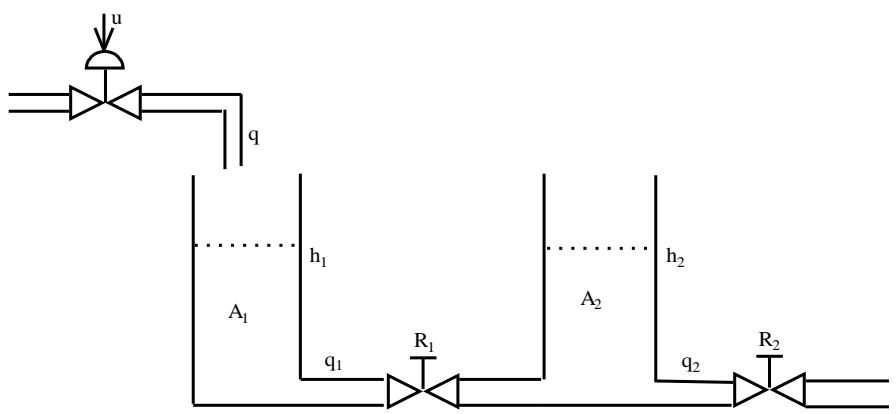

Figure 1. Block Diagram of Coupled two tank liquid system

\section{Modeling of Coupled Two Tank Liquid System}

When two tanks are joined together the coupled tank system is formed as shown in figure 2 . In the coupled tank the system states are the level $H_{1}$ in tank 1 and the level $\mathrm{H} 2$ in tank 2.If the control input is the pump flow rate Q1, then the variable to be controlled would normally be the second state the level $\mathrm{H} 2$, with disturbances caused by variations in the rate of flow out of the system by valve B. It is necessary to build a model for each of the tank levels.

For Tank 1 the flow balance equation is

$$
Q_{i}-Q_{b}=A \frac{d H_{1}}{d t}
$$

where, new variable is the flow rate $\mathrm{Q}_{\mathrm{b}}$ of fluid from tank 1 to tank 2 through valve $\mathrm{B}$.

For Tank 2 the flow balance equation is

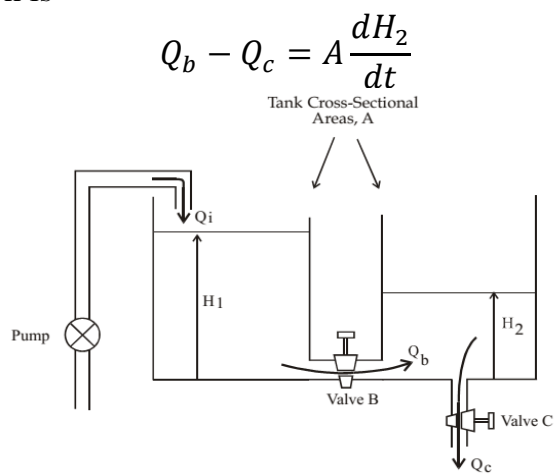

Figure 2. Coupled two tank liquid system

The system model comes from the nonlinear equations and the two flow balances through the valves. The system non linearity is again a square root law if the valves are ideal orifices.

$$
\begin{gathered}
Q_{i}-C_{d b} a_{b} \sqrt{2 g\left(H_{1}-H_{2}\right)}=A \frac{d H_{1}}{d t} \\
C_{d b} a_{b} \sqrt{2 g\left(H_{1}-H_{2}\right)}-C_{d c} a_{c} \sqrt{2 g H_{2}}=A \frac{d H_{2}}{d t}
\end{gathered}
$$

Equations describe the coupled tanks system dynamics in its non-linear form with ideal equations for the valves. The square root law is only an approximation in general applications. To design the control systems for the coupled tanks the equations are linearised by considering small variations qi, h1 and $h 2$. The variations are measured with respect to the normal operating levels. 


\section{Mathematical Modeling of the System}

The state variable model for the two tank liquid level system is

$$
\left[\begin{array}{c}
\dot{\mathrm{h}_{1}} \\
\dot{\mathrm{h}_{2}}
\end{array}\right]=\left[\begin{array}{cc}
-1 & 1 \\
1 & -2
\end{array}\right]\left[\begin{array}{l}
\mathrm{h}_{1} \\
\mathrm{~h}_{2}
\end{array}\right]+\left[\begin{array}{l}
1 \\
0
\end{array}\right] \mathrm{q}
$$

The required time constants corresponds to the Eigen value location $\mathrm{s}_{1}=-5, \mathrm{~s}_{2}=-20$. The corresponding characteristic equation is

$$
(s+5)(s+20)=s^{2}+25 s+100=0
$$

Step 1 : To check whether the system is completely controllable

$$
\begin{gathered}
\text { Controllability matrix } \mathrm{M}=\left[\begin{array}{ll}
\mathrm{B} & \mathrm{AB}
\end{array}\right] \\
\begin{array}{c}
\mathrm{AB}=\left[\begin{array}{cc}
-1 & 1 \\
1 & -2
\end{array}\right]\left[\begin{array}{l}
1 \\
0
\end{array}\right]=\left[\begin{array}{c}
-1 \\
1
\end{array}\right] \\
\text { Therefore } \mathrm{M}=\left[\begin{array}{cc}
1 & -1 \\
0 & 1
\end{array}\right] \\
|\mathrm{M}|=1
\end{array}
\end{gathered}
$$

The determinant of matrix $\mathrm{M}$ is not zero, therefore Rank $=2$ and rank =order of the system. So the system is completely controllable is verified.

Step 2 : Find $(\mathrm{sI}-\mathrm{A})$

$$
\begin{aligned}
(\mathrm{sI}-\mathrm{A}) & =\left[\begin{array}{ll}
\mathrm{s} & 0 \\
0 & \mathrm{~s}
\end{array}\right]-\left[\begin{array}{cc}
-1 & 1 \\
1 & -2
\end{array}\right] \\
& =\left[\begin{array}{cc}
\mathrm{s}+1 & -1 \\
-1 & \mathrm{~s}+2
\end{array}\right] \\
|(\mathrm{sI}-\mathrm{A})| & =\mathrm{s}^{2}+3 \mathrm{~s}+1=0
\end{aligned}
$$

Comparing the above equation with general equation $\mathbf{s}^{2}+\mathbf{a}_{1} \mathbf{s}+\mathbf{a}_{2}=\mathbf{O}$, the values are $\mathrm{a}_{1}=3$ and $\quad \mathrm{a}_{2}=1$

Step 3 : To covert the system in state controllable form. $\mathrm{T}=\mathrm{MW}$ where ' $\mathrm{T}$ ' is a transformation matrix that transforms the system equation into the state controllable canonical form and it is used to find out the feedback gain matrix K.

$$
\begin{gathered}
\mathrm{W}=\left[\begin{array}{ll}
\mathrm{a}_{1} & 1 \\
1 & 0
\end{array}\right]=\left[\begin{array}{ll}
3 & 1 \\
1 & 0
\end{array}\right] \\
\mathrm{T}=\mathrm{MW}=\left[\begin{array}{cc}
1 & -1 \\
0 & 1
\end{array}\right] *\left[\begin{array}{ll}
3 & 1 \\
1 & 0
\end{array}\right]=\left[\begin{array}{ll}
2 & 1 \\
1 & 0
\end{array}\right]
\end{gathered}
$$

Step 4 : The desired characteristic equation is $(s+5)(s+20)=s^{2}+25 s+100=0$

Comparing with general equation $\mathrm{s}^{2}+\alpha_{1} \mathrm{~s}+\alpha_{2}=0$, We get $\alpha_{1}=25$ and $\alpha_{2}=100$

Step 5 : The feedback gain matrix $\mathrm{K}$ is obtained as

$$
\mathrm{K}=\left[\begin{array}{ll}
\alpha_{2}-\mathrm{a}_{2} & \alpha_{1}-\mathrm{a}_{1}
\end{array}\right] \mathrm{T}^{-1}
$$




$$
\begin{gathered}
\mathrm{K}=\left[\begin{array}{cc}
100-1 & 25-3
\end{array}\right] \mathrm{T}^{-1} \\
\mathrm{~T}^{-1}=\left[\begin{array}{cc}
0 & 1 \\
1 & -2
\end{array}\right] \\
\mathrm{K}=\left[\begin{array}{ll}
99 & 22
\end{array}\right]\left[\begin{array}{cc}
0 & 1 \\
1 & -2
\end{array}\right] \\
\mathrm{K}=\left[\begin{array}{ll}
22 & 55
\end{array}\right]
\end{gathered}
$$

Therefore the required feedback control law is

$$
\mathrm{u}=-\mathrm{KX}=\left[\begin{array}{ll}
22 & 55
\end{array}\right]\left[\begin{array}{l}
\mathrm{h}_{1} \\
\mathrm{~h}_{2}
\end{array}\right]=-22 \mathrm{~h}_{1}-55 \mathrm{~h}_{2}
$$

\section{Simulation Results}

Simulation studies are performed by using MATLAB-SIMULINK to verify the proposed two tank system level process with integral control State feedback controller.

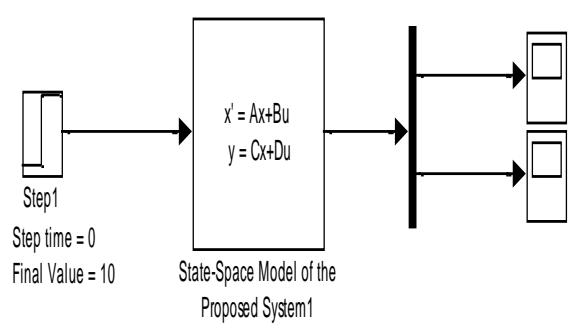

Figure 3. Open loop response without disturbance

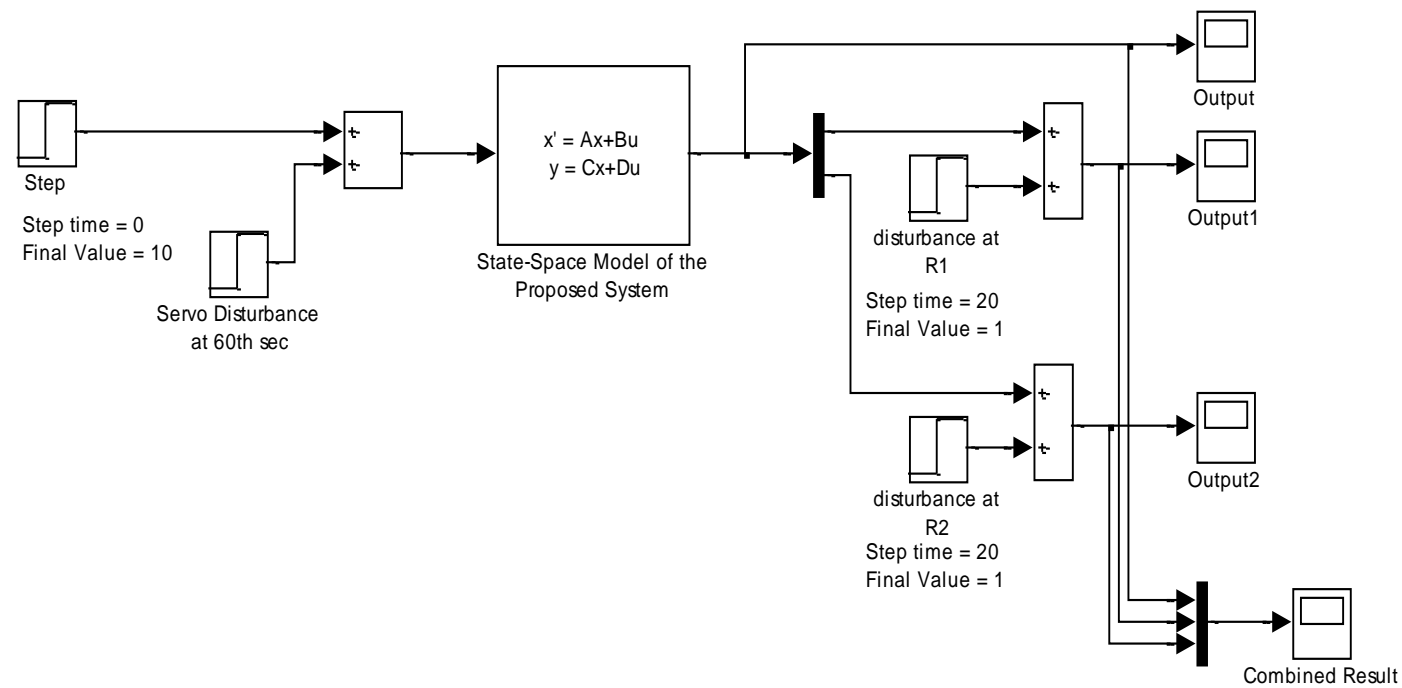

Figure 4. Open loop response with disturbance 


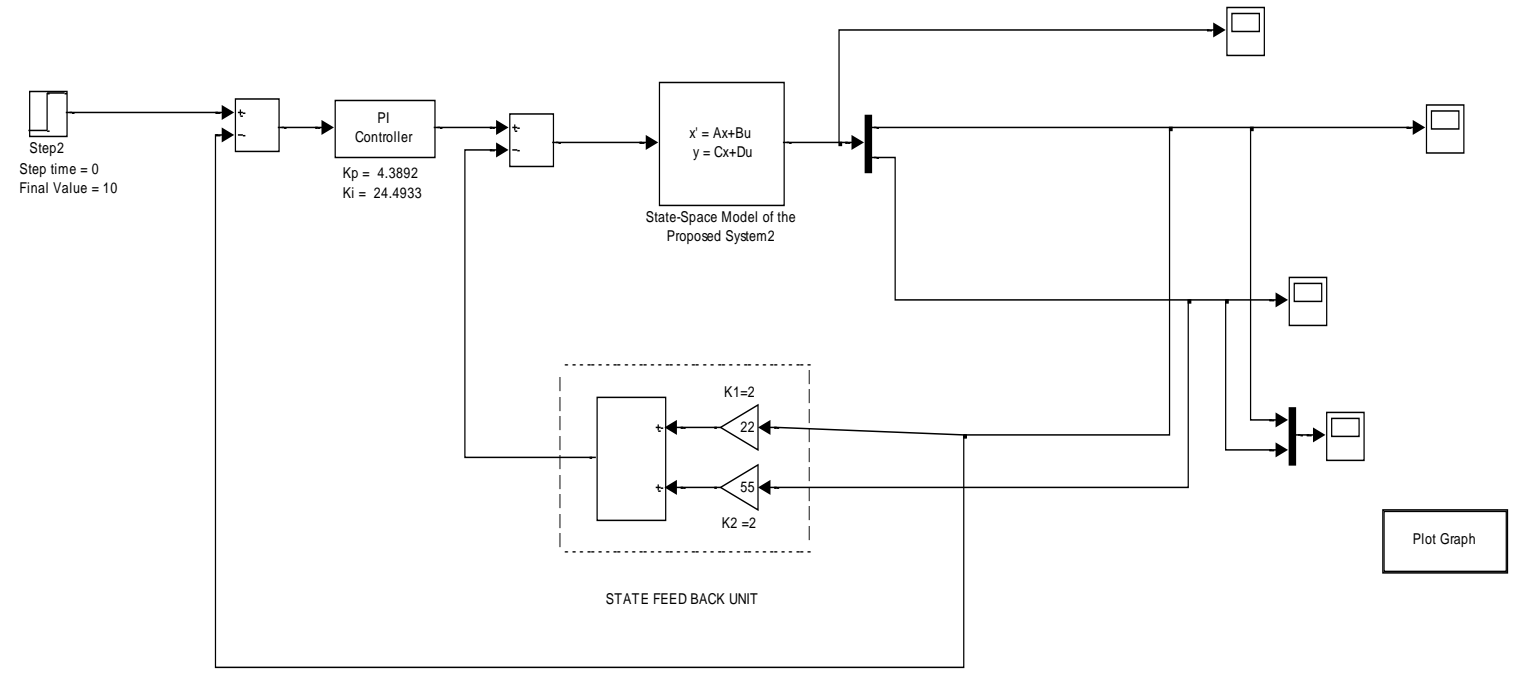

Figure 5. Closed loop response without disturbance

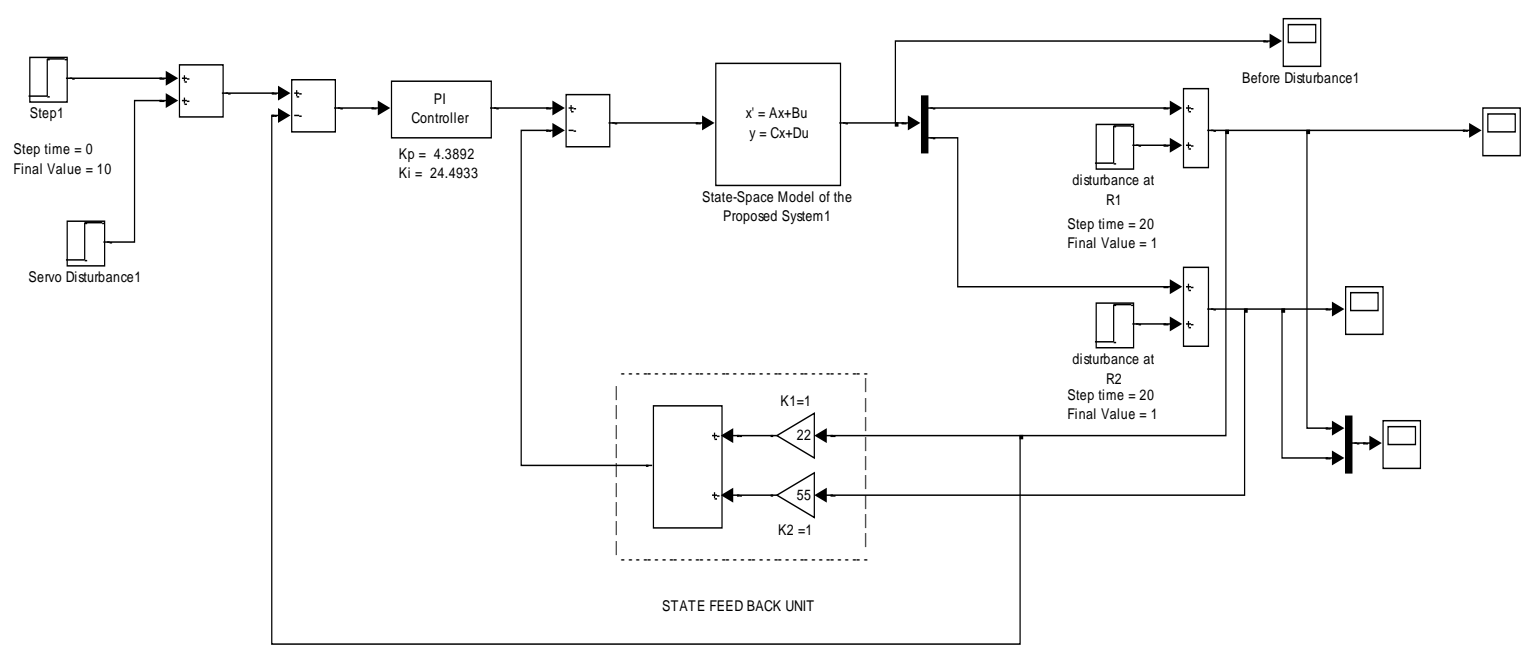

Figure 6. Closed loop response with disturbance

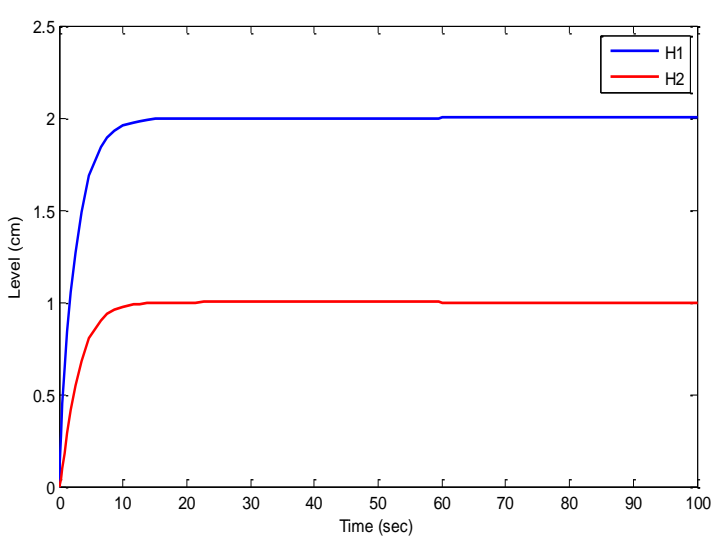

Figure 7 . Open loop response without disturbance

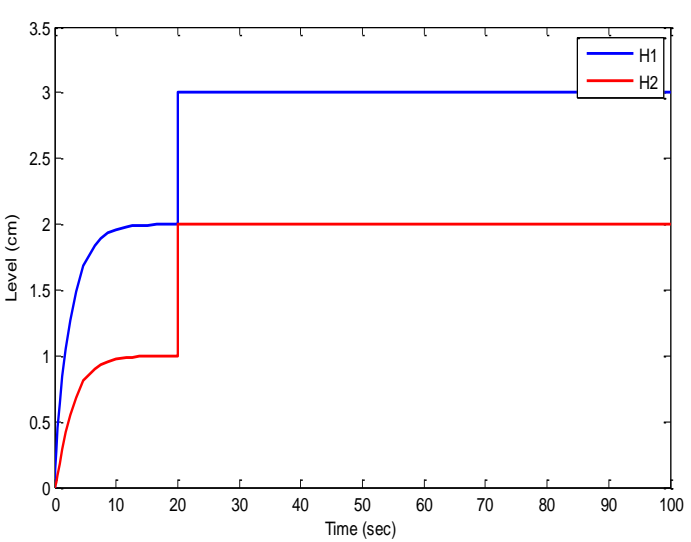

Figure 8. Open loop response with Servo disturbance 

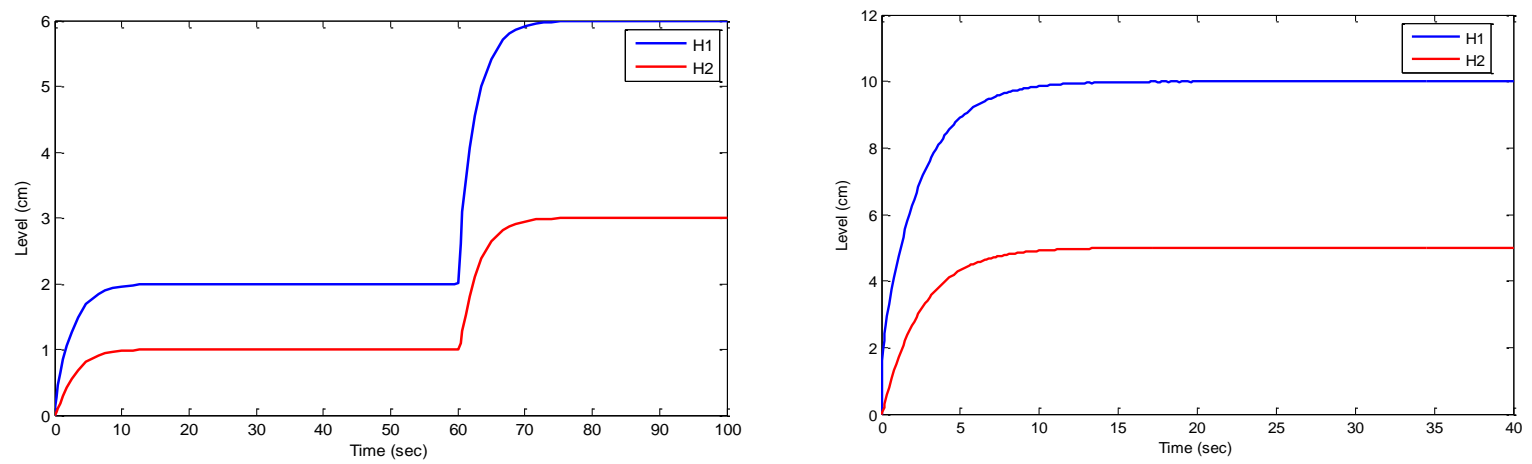

Figure 9. Open loop response with Regulatory disturbance Figure 10. Closed Loop Servo Nominal response

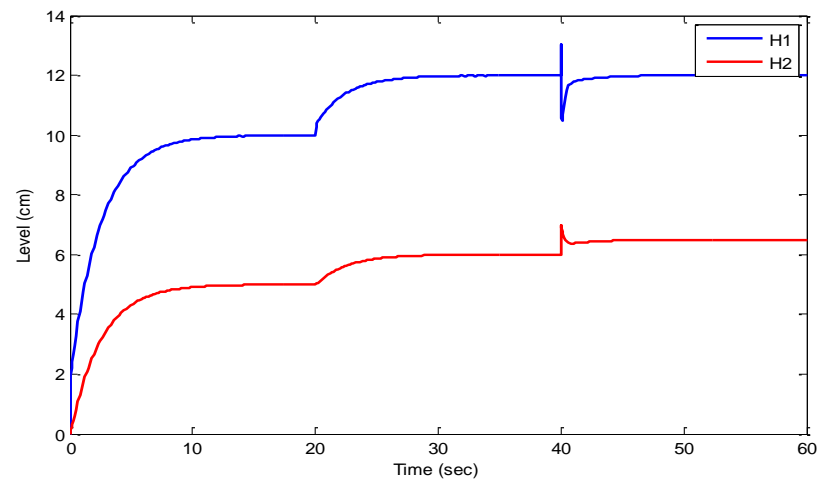

Figure 11. Closed Loop response with servo and regulatory disturbances

\section{Conclusion}

System designed with state feedback control system can perform well in servo and regulatory conditions. If the state variables are used for feedback then the system can be optimized for satisfying a desired performance index. The limitations in state feedback method are that all the state variables are measurable and are available for feedback and also the cost associated with placing all closed-loop poles.

\section{Acknowledgement}

The authors would like to thank the anonymous reviewers for their comments which will be very helpful in improving the quality and presentation of this paper.

\section{References}

[1] Albert.G, Beth.T, Horodecki.M, Horodecki.P, Horodecki.R, Rotteler (2000) Lecture notes.

[2] Astrom K.J and Wittenmark (1997) Computer-controlled systems. Prentice Hall.

[3] Bainov.D.D and. Simeonov P.S (1989) Systems with impulse effect: stability, theory and applications. Ellis Horwood Limited.

[4] Figueiredo.A, Gleria, and Rocha (2000) Boundedness of solutions and Lyapunov functions in quasi-polynomial systems. Physics Letters A, 268:335-341.

[5] Findeisen.F,. Imsland.L,. Allgover.F, and Foss (2005) State and output feedback nonlinear model predictive control: An overview. European Journal of Control, 9:No. 2-3.

[6] Gahinet.P, Nemirovski.A, Laub, and Chilali (1995) LMI Control Toolbox Users Guide. The MathWorks, Inc.

[7] Gleria.I.M, Figueiredo.A, and Rocha Filho (2003) A numerical method for the stability analysis of quasi-polynomial vector fields. Nonlinear Analysis, 52:329-342.

[8] Hangos.K.M, Bokor.J, and Szederkenyi (2004) Analysis and Control of nonlinear Process Systems. Springer-Verlag.

[9] Hangos.K.M and Cameron.I.T (2001) Process modelling and model analysis. Academic Press, London.

[10] Helstrom.C.W (1976) Quantum decision and estimation theory. Academic Press, New York.

[11] Hernandez-Bermejo.B (2002) Stability conditions and Lyapunov functions for quasi polynomial systems. Applied Mathematics Letters, 15:25-28.

[12] Isidori.A (1995) Nonlinear Control Systems. Springer-Verlag.

[13] Marquardt.W and Monnigmann.M (2005) Constructive nonlinear dynamics in process systems engineering. Computers \& Chemical Engineering, 29:1265-1275.

[14] Nguyen H.T (1998) Analogue and Digital Control, UTS Lecture notes.

[15] Stillman.K (1996) Control Engineering I, UTS Lecture notes.

[16] Weinfurter.H, Werner.R, and Zeilinger (2001) Quantum Information. Springer. 